\title{
СИНДРОМ КУБИТАЛЬНОГО КАНАЛА: ДИАГНОСТИКА И ВЫБОР ТАКТИКИ ЛЕЧЕНИЯ
}

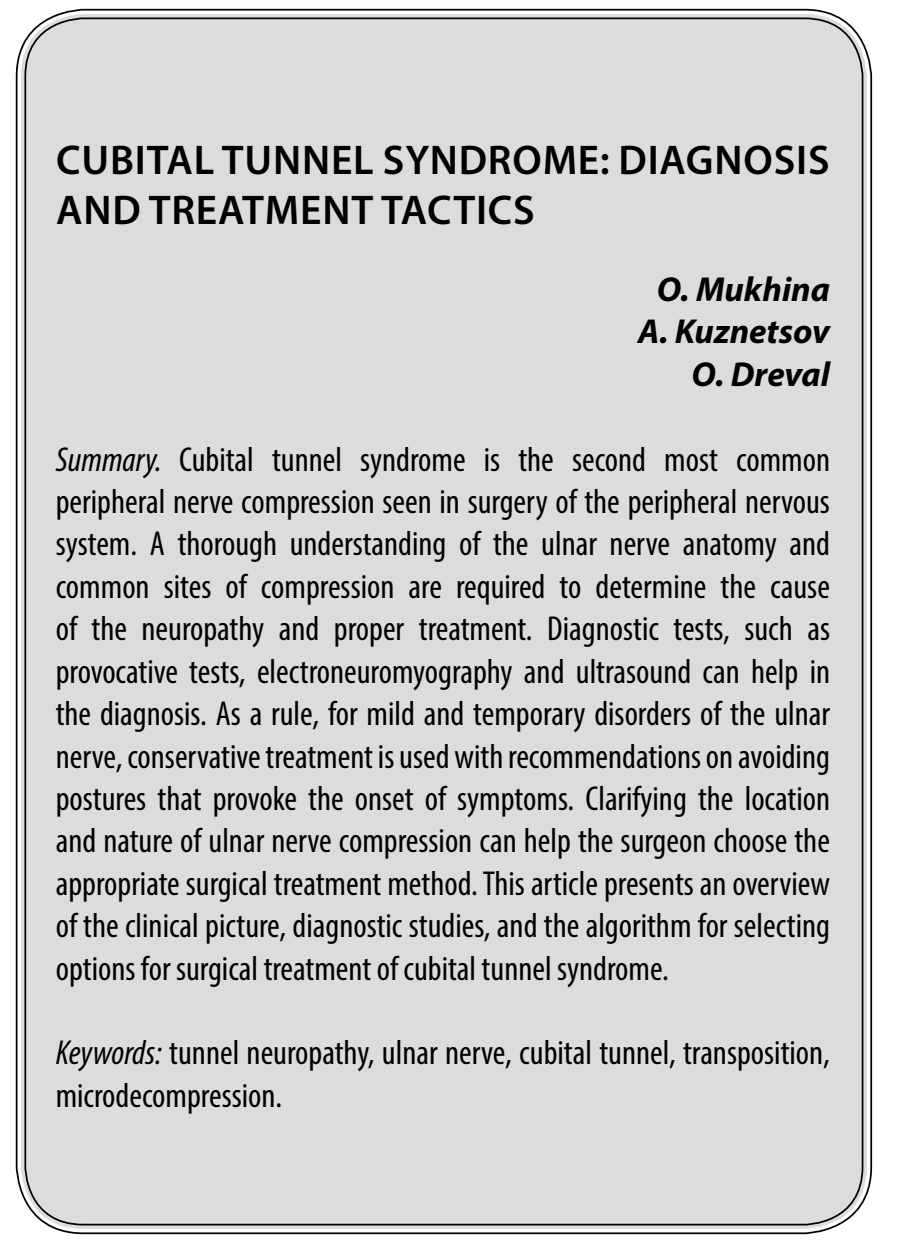

$\mathbf{K}$ омпрессия на уровне локтевого сустава остается одной из наиболее распространенных форм локтевой невропатии и представляет собой вторую наиболее встречаемую причину компрессии нервов верхних конечностей. [2].

Этиологически данная патология имеет общие причины возникновения с другими туннельными нейропатиями, в основе развития которых лежит компрессионный механизм. Туннельные нейропатии широко распространены (до 45,8\%) у лиц, профессиональная деятельность которых связана с длительным напряжением отдельных групп мышц или определенных стереотипных движениях, однако в связи с повышением информированности населения, доступности диагностических методов обследования можно говорить и об относительно значимой представленности данного заболевания среди населения в целом.[8] При развитии заболевания опре-
Мухина Ольга Владимировна

Ассистент, Российская медицинская академия непрерывного профессионального образования

personal1@mail.ru

Кузнецов Алексей Витальевич

К.м.н., дочент, Российская медицинская академия непрерывного профессионального образования

Древаль Олег Николаевич

Д.м.н., профессор, Российская медицинская академия непрерывного профессионального образования

Аннотация. Кубитальный туннельный синдром является вторым наиболее распространенным синдромом компрессии периферических нервов, который наблюдают в группе заболеваний периферических нервов. Для определения причины невропатии и правильного лечения необходимо понимание анатомических структур локтевого нерва и возможных мест компрессии. Диагностические исследования, такие как провокационные пробы, электронейромиография и ультразвуковое исследование, помогают при постановке диагноза. Как правило, при легких и временных нарушениях со стороны локтевого нерва применяется консервативное лечение с рекомендациями об избегании поз, провоцирующих возникновение симптомов, изменении специфической нагрузки. Уточнение места и характера компрессии локтевого нерва помогает хирургу выбрать соответствующую методику хирургического лечения. В данной статье представлены обзор клинической картины, диагностических исследований и алгоритм выбора варианта хирургического лечения кубитального туннельного синдрома.

Ключевые слова: туннельные невропатии, локтевой нерв, кубитальный канал, транспозиция, микродекомпрессия.

деляющим становится непосредственно расположение локтевого нерва в области локтевого сустава. Особенность его местоположения состоит в том, что нерв, защищённый лишь мягкотканой структурой, сохраняет постоянный контакт с костными структурами, подвергаясь статической и динамической травматизации. Анатомические врожденные аномалии, как правило, не приводят к клиническим проявлениям, но могут являться предрасполагающими факторами. Это особенно актуально для обычных бессимптомных вывихов локтевого нерва. Однако, неправильно сросшийся дистальный перелом плечевой кости с деформацией сустава, вальгусной или варусной, или остеоартроз приводят к формированию экзостозов, оказывающих прямое воздействие на нерв. Кроме того, вторичный кубитальный синдром может возникнуть при ревматоидном артрите, пролиферативном синовиите и при болезни Педжета. Такие поражения как синовиальные ганглии, утолщенные вены или кисты 


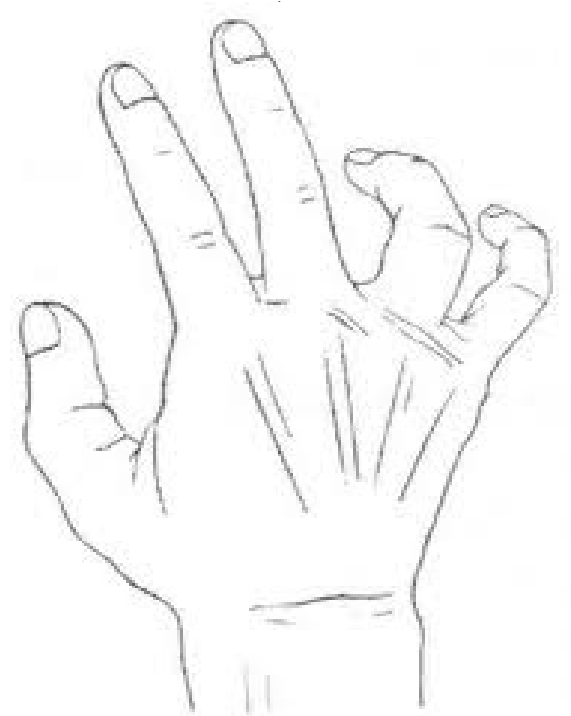

Рис. 1. Вид «когтистой лапы»

в локтевом туннеле также могут приводить к синдрому кубитального канала. Также ряд метаболических и генетически опосредованных факторов могут предрасполагать к компрессии периферических нервов, именно поэтому у пациентов на этапе дообследования следует исключать системные и метаболические заболевания, генерализованные нейропатии, поскольку в данном случае лечение этих заболеваний будет основным. [2,4]

\section{Клинические проявления синАрома кубита^ьного кана^а}

Несмотря на большое количество доступной информации о кубитальном туннельном синдроме, ранняя постановка диагноза остается определенной проблемой, поскольку пациенты зачастую не осознают наличие заболевания до тех пор, пока симптомы не станут достаточно выраженными.

Локтевой нерв, как смешанный, манифестирует с онемения и мышечной слабости в зоне иннервации. Наступление симптомов либо их выраженная прогрессия могут быть острым («за ночь»): онемение 4, 5 пальцев кисти, реже предплечья по локтевой стороне [6]. В течение дня онемение может проходить самостоятельно, что обуславливает редкую обращаемость пациентов на этой стадии. Сдавление локтевого нерва приводит к дальнейшим чувствительным нарушениям с тыльной стороны кисти как следствие поражения задней кожной ветви локтевого нерва. Через некоторое время появляется слабость («неуклюжесть») кисти, возможна болезненность при пальпации нерва в области локтевого сустава. Атрофия мышц кисти (межкостных, червеобразных, возвышений мизинца и I пальца) приводит к стойким нейрогенным контрактурам и при несвоевременном лече- нии заболевания кисть приобретает форму «когтистой лапы». [8].

Основными, ведущими признаками поражения локтевого нерва являются атрофия мышцы, отводящей мизинец, атрофия в области «анатомической табакерки», онемение 4-5 пальцев кисти. У большинства пациентов, как правило, наблюдаются как сенсорные, так и моторные нарушения, причем последние указывают на более поздние проявления, которые, в свою очередь, соответствуют менее благоприятному прогнозу. [13]

Особенности поражения определенных мышц кисти определяют характерные положительные функциональные пробы.

Наиболее часто применяемые диагностические тесты:

- при попытке разгибания пальцев происходит неполное разгибание 5, 4 и отчасти 3 пальца,

- невозможно «царапание» мизинцем по столу при плотно прилегающей к столу кисти,

- при плотно прилегающей к столу кисти невозможны разведение и приведение пальцев,

- попытка зажатия бумаги большим пальцем кисти без сгибания дистальной фаланги затруднена или невозможна.

\section{$\triangle$ иагностика}

Диагноз компрессионно-ишемической невропатии на уровне кубитального канала ставится на основании данных анамнеза, характерного симптомокомплекса, положительных функциональных проб и дополнительных нейрофизиологических исследований (электро- 
нейромиографии) и нейровизуализационных методов обследования (УЗИ, рентгенографии или МРТ при показаниях). [2] В последнее время использование высокоразрешающего ультразвукового исследования стало важным диагностическим инструментом, дающим представление о морфологических изменениях нерва в пределах кубитального туннеля [1]. Дифференциальная диагностика имеет важное значение и должна исключать радикулопатию $C 8$, поражение нижнего пучка плечевого сплетения, дебют полинейропатий, вторичные причины в виде объемных образований локтевого нерва, вальгусной деформации локтевого сустава, остеофитов медиального надмыщелка.

Одним из основных методов, способствующих дифференциальной диагностике, является электронейромиография (ЭНМГ). Электрофизиологическое исследование локтевого нерва позволяет установить наличие повреждения, локализовать его область, исключить другие заболевания, имитирующие локтевую нейропатию, а также обладает прогностической ценностью в отношении возможного выздоровления. ЭНМГ в большей степени необходима именно для исключения более распространенных повреждений, таких как поражения плечевого сплетения, периферические наследственные или метаболические нейропатии. [4] Оценка результатов электромиографии всегда должна проводиться с учетом клинической картины. По данным литературы, ЭНМГ признаки поражения локтевого нерва в области локтя могут выявляться примерно у 15\% здоровых добровольцев, и это значение увеличивается до $30 \%$ у лиц старше 60 лет [6]. Дополнительной информацией врача обеспечивают игольчатая электромиография (ЭМГ) и исследование проводимости нервов. Игольчатая ЭМГ позволяет выявить признаки денервации в мышцах исследуемого нерва и, исходя из анатомического распределения денервированных и интактных мышц, судить об уровне его поражения. При локтевой нейропатии в программу исследования обязательно должны входить: первая межкостная мышца, локтевой сгибатель кисти, мышца, отводящая мизинец. Наиболее часто изменения при компрессии локтевого нерва возникают именно в первой межкостной мышце [7].

Исследование проводимости нерва в большинстве случаев позволяет диагностировать синдром кубитального канала. Стоит отметить, что важным условием для этого исследования является правильное положение руки пациента: во время исследования и при измерениях рука должна быть согнута в локте на 70-90․ Разогнутое положение руки может привести к ложному замедлению скорости распространения возбуждения (СРВ) в области локтя [7]. Для повышения достоверности в исследование проведения по локтевому нерву обязательно следует включать несколько точек стимуляции: прок- симальнее лучезапястного сустава, на 2-3 см дистальнее медиального надмыщелка плечевой кости, на $10 \mathrm{~cm}$ проксимальнее предыдущей точки стимуляции и в подмышечной ямке либо в межлестничном пространстве. Соблюдение данного условия позволяет у большинства пациентов дифференцировать поражения в области верхней апертуры грудной клетки, канале Гийона и в кубитальном канале.

Как правило, изменения по данным ЭНМГ при компрессионно-ишемической нейропатии локтевого нерва на уровне кубитального канала включают в себя: локальное замедление скорости распространения возбуждения (СРВ) как по моторным, так и по сенсорным волокнам, а также наличие блока проведения по моторным волокнам при стимуляции нерва выше локтя. В сегменте нерва, расположенном дистально по отношению к месту компрессии, также можно наблюдать замедление СРВ, обычно вместе со снижением амплитуды М-ответа. Эта находка обычно является следствием дегенерации аксона[8].

Нельзя не отметить, что объективность результатов обследования в значительной степени зависит от человеческого фактора и применяемой методики [13]. Так, к примеру, наличие анастомоза Мартина-Грубера по данным электромиографии можно ошибочно принять за сдавление локтевого нерва.

Несмотря на все достоинства применения ЭНМГ в диагностике кубитального туннельного синдрома, оно имеет некоторые ограничения, такие как дискомфорт для пациентов, возможные трудности с точной локализацией, невозможность выявления структурных аномалий, вероятность ложноотрицательных результатов и трудоемкость процесса.

Во многих работах последних лет ультразвуковое исследование локтевого нерва показало свою высокую валидность для верификации и уточнения характера патологии при кубитальном синдроме. [1] Такое исследование позволяет получить информацию об особенностях поражения или окружающих анатомических образованиях, а также обеспечить оптимальную визуализацию архитектоники и морфологии нерва.

При рассматриваемой патологии по данным УЗИ отчетливо визуализируются изменения структуры нервного ствола в зависимости от уровня компрессии: над уровнем компрессии - увеличение площади поперечного сечения по сравнению с противоположной верхней конечностью, при условии, что процесс не двусторонний [12], торсию, отек и набухание нерва, дистальнее уровня компрессии - истончение и потерю морфоструктуры нерва. 
В большинстве случаев оценивают поперечное сечение локтевого нерва на четырех уровнях: четыре сантиметра проксимальнее медиального надмыщелка плеча (МНП), на уровне МНП, четыре сантиметра дистальнее МНП, а также максимальное значение между этими точками [9]. При таком подходе возможно верифицировать увеличение объема сухожилий вблизи нерва, воспалительные явления МНП, дислокацию локтевого нерва, либо изменения нерва за счет собственных оболочек нерва.

Наряду с исследованием поперечного сечения нерва, также необходимо проводить исследование локтевого нерва в продольном направлении. Данный метод позволяет оценить нерв на протяжении с захватом нескольких областей: до входа в канал, в самом канале и на выходе из кубитального канала, что позволяет с высокой вероятностью диагностировать структурные изменения и особенности самого нерва, а также индивидуализировать хирургическую тактику по отношению к конкретному пациенту на основании полученных данных.

Соответствие данных ультразвуковых исследований клиническим данным по результатам разных авторов составляет 80-93\% [7]. Безусловно, точность исследования и его интерпретации варьируется в зависимости от опыта и способностей оператора, а также класса ультразвукового аппарата.

\section{^ечение}

Консервативное лечение при синдроме кубитального канала наиболее эффективно на начальных стадиях заболевания, когда симптомы носят преходящий характер. Лечебные мероприятия направлены на модификацию бытовых и профессиональных привычек пациента (опора на локоть на рабочем месте, сон на максимально согнутой в локте руке), возможно применение приспособлений, ограничивающих сгибание в локте. В ряде рандомизированных контролируемых исследований доказано, что знание пациента о механизме травмирования нерва и возможности избежать определенных провоцирующих поз и движений приводит к значительному уменьшению симптомов $[2,8]$

Если консервативное лечение не предотвращает прогрессирование заболевания в течение нескольких месяцев либо при обращении пациента с уже выраженными формами нейропатии (с постоянным онемением, мышечными атрофиями) становится актуальным хирургическое лечение. Этиологическим методом лечения компрессионной формы нейропатии является устранение компрессии и создание условий для свободного расположения нерва в узком туннеле. Хирургическое лечение может состоять только из простой декомпрессии нерва, микродекомпрессии, декомпрессии с передней транспозицией локтевого нерва (подкожной, межмышечной или подмышечной). [2]

Основная цель оперативного лечения - избежать прогрессирования симптомов со стороны локтевого нерва, а именно развития атрофии мышц и формирования контрактур. Руководствуясь этим, декомпрессия должна проводиться согласно следующим принципам: высвобождение всех возможных мест компрессии; сохранение васкуляризации локтевого нерва и его естественного положения при отсутствии противопоказаний.

При невыраженной и умеренной стадии заболевания для достижения положительного результата с незначительной травматизацией тканей в качестве метода выбора хирургической техники выступает декомпрессия локтевого нерва в виде невролиза, которая может выполняться как открытым способом, так и эндоскопически. [3] Однако, существуют исследования, показывающие, что, прибегая к простой декомпрессии нерва, при наличии в проекции кубитального канала патологических мягкотканых и костных структур, нарушающих нормальную анатомию рассматриваемой области, может достигаться лишь временное улучшение и впоследствии наблюдается рецидив заболевания [10].

В связи с этим, альтернативным вариантом хирургического лечения синдрома кубитального канала является декомпрессия локтевого нерва с дальнейшей его транспозицией. Достаточное количество работ показывают положительные результаты данного вида хирургического лечения, несмотря на высокую травматизацию тканей [13] Наиболее распространены два вида передней транспозиции локтевого нерва. Первый, подкожный, предусматривает перемещение нерва непосредственно под поверхностные ткани (кожа), второй - в сформированный межмышечный канал в мышцах-сгибателях кисти и пальцев. В подобных случаях существует определенный процент осложнений в виде усугубления нейропатии из-за постоянного механического воздействия на локтевой нерв в области сустава, формирования рубцового процесса, а также повреждения мышечно-кожного нерва предплечья. Ряд исследований демонстрируют необходимость повторных хирургических вмешательств для купирования выраженного болевого синдрома [10].

Методика медиальной эпикондилэктомии описана для использования только при стойкой дислокации локтевого нерва на переднюю поверхность надмыщелка вследствие выраженной посттравматической деформации. 


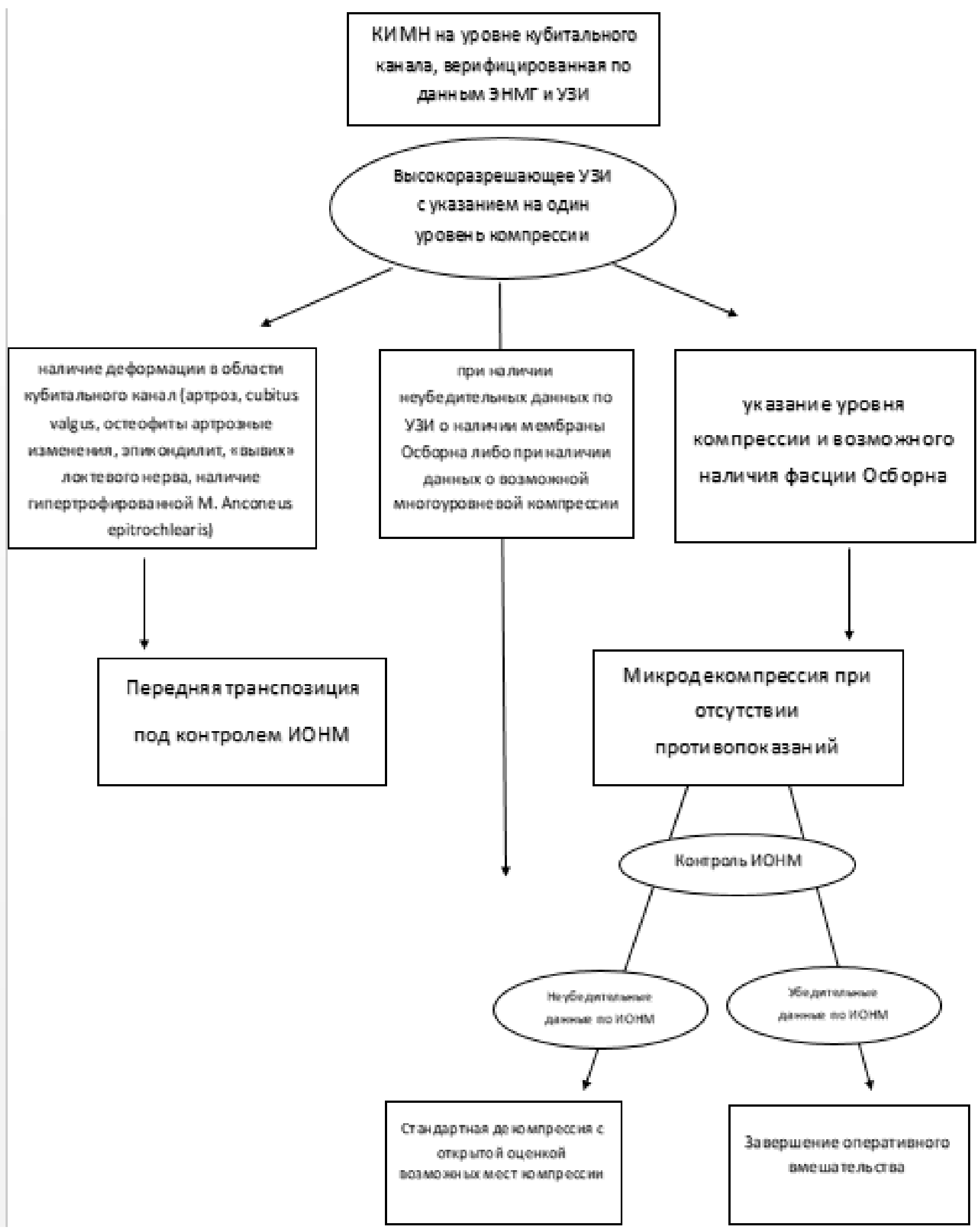

Схема 1. Алгоритм выбора метода хирургического лечения на основании данных предоперационного и интраоперационного обследования. 
В литературе приведены различные результаты сравнения эффективности декомпрессии локтевого нерва на уровне кубитального канала с транспозицией локтевого нерва, однако в большинстве своем эффективность этих двух методов сопоставима между собой [12].Тем не менее, отмечается большая частота различных осложнений при сочетании декомпрессии с транспозицией локтевого нерва [3].

В проведенном нами исследовании с 2016 по 2019 гг. сравнивались три наиболее распространенные методики хирургического лечения синдрома кубитального канала, а именно стандартная декомпрессия, декомпрессия с передней транспозицией и микродекомпрессия. Алгоритм обследования пациентов на предоперационном этапе, кроме клинико-анамнестических данных и результатов провокационных проб, включал в себя ЭНМГ, УЗИ высокого разрешения, при наличии показаний - рентгенографию локтевого сустава. Оперативные вмешательства выполнялись под контролем интраоперационного нейромониторинга с соблюдением всех современных требований хирургии периферической нервной системы. Ключевую роль в выборе методики играли дополнительные сведения об особенностях компрессии и строения кубитального канала, полученные во время ультразвукового исследования, а также данные интраоперационного нейромониторинга.

По данным исследования выявлено, что восстановление функции локтевого нерва при стандартной и микро- декомпрессии было практически одинаково ( $>>0,05)$, но получены несколько более худшие результаты в группе с транспозицией, что, вероятнее всего, связано с изменением анатомии расположения нерва и возможными сосудистыми поражениями локтевого нерва на фоне деформации в области кубитального канала[5]. При меньшей хирургической агрессии метод микродекомпрессии позволил добиться результатов, схожих с показателями применения других хирургиче- ских методик. Противопоказаниями к использованию данного метода можно считать наличие нескольких уровней компрессии локтевого нерва на протяжении его хода по данным УЗИ, ожирение, повторное вмешательство, а также травматическое повреждение. При неудовлетворительных данных о результативности выполняемой микродекомпрессии по данным интраоперационного нейромониторинга, производилась конверсия метода в сторону стандартной декомпрессии либо декомпрессии с транспозицией. Согласно полученным результатам, был сформирован алгоритм выбора метода хирургического лечения на основании данных предоперационного и интраоперационного обследования (схема 1).

\section{Выво $\triangle \mathrm{b}$}

Раннее распознавание заболевания и эффективное его лечение имеют первостепенное значение для получения хороших клинических результатов в лечении синдрома кубитального канала, помогая избежать необратимой атрофии мышц и дефицита функции. Участки компрессии нерва могут носить мультифокальный характер, что требует полного анатомического понимания хода локтевого нерва, правильной интерпретации данных нейровизуализации и функционального состояния нерва.

Консервативные меры могут быть успешными у многих пациентов, но наиболее приемлемы для тех, у кого симптомы заболевания являются легкими и непостоянными. Для пациентов с резистентными к консервативным мерам симптомами хирургические варианты, включая микродекомпрессию, декомпрессию локтевого нерва с передней транспозицией или без нее, остаются основой лечения. Данные дополнительных методов обследования на пред- и интраоперационном этапах позволяют индивидуализировать выбор применяемого метода хирургического лечения, повысив его эффективность и удобство для пациента.

\section{ЛИТЕРАТУРА}

1. Айтемиров, Ш. М. Высокоразрешающая ультрасонография в диагностике и хирургии периферических нервов конечностей (обзор литературы). / Ш. М. Айтемиров, В. Г. Нинель, Г. А. Коршунова // Травматология и ортопедия России. - 2015. — № 3. - C. 116-125

2. Древаль, О. Н. Клинические рекомендации по диагностике и хирургическому лечению повреждений и заболеваний периферической нервной системы. / 0. Н. Древаль, А. В. Кузнецов, Р. С. Джинджихадзе, В. Л. Пучков, В. П. Берснев // Ассоциация нейрохирургов России.— Москва, 2015.— 34 с.

3. Лэн, 3. Д. Результаты минимально инвазивного подхода в лечении синдрома кубитального канала. / З. Д. Лэн и соавторы // Журнал клинической нейрохирургии - 2015. - № 22. - С. 964-968.

4. Мозолевский, Ю. В. Заболевания периферической нервной системы. Практическое руководство/ Ю. В. Мозолевский. — Москва, 2019. — $432 c$.

5. Мухина, О. В. Хирургические методы лечения туннельной невропатии локтевого нерва на уровне кубитального канала. / Мухина 0. В., Кузнецов А. В., Древаль 0. Н., Федяков А. Г. // Российский нейрохирургический журнал им. А. Л. Поленова Т. ХІ — СПб., 2019.— № 1.— С. 48-53

6. Нинель, В. Г. Комплексная диагностика в тактике хирургического лечения повреждений периферических нервов конечностей. / В. Г. Нинель, Ш. М. Айтемиров, Г. А. Коршунова // Вестник травматологии и ортопедии им. Н. Н. Приорова.— 2016. — № 1.— С. $62-66$. 
7. Омежек, Дж. Диагностическая точность ультразвуковой диагностики и исследования проводимости нерва при локтевой ульнарной невропатии. / Дж. Омежек, Т. Згур, С. Поднар // Клиническая нейрофизиология — 2015 — № 126(9) — С. 1797-1804.

8. Попелянский Я. Ю. Болезни периферической нервной системы: руководство для врачей / Я. Ю. Попелянский. - 4-е изд.- М.: МЕДпресс-информ, 2018. - 352c.

9. Ристегини, Питер. Ультразвуковая диагностика болезней костно-мышечной системы. / Питер Ристегини // 2019-256с.

10. Халид, Сейд. Современная минимально-инвазивная техника в лечении кубитального туннельного синдрома. / Сейд И. Халид, Адам Карлтон, Райан Келли, Джонатан Цитоу // Журнал спинальной хирургии. — 2019 — № 5(1) — c. 88-96

11. Хардер, К. Результаты простой декомпрессии локтевого нерва при синдроме кубитального канала. /К. Хардер, С. Лукшу, С. Е. Дунда и соавторы.// Междисциплинарная Пластическая и Реконструктивная Хирургия. - 2015 — № 4.

12. Эндрюс, Кайл. Кубитальный туннельный синдром: анатомия, клиническая картина и лечение. / Кайл Эндрюс, Андреа Роуланд, Анкур Пранжал, Набил Эбрагейм // Журнал Ортопедии.—-2018 — № 15.- С. 832-836.

13. Яха, Аэша. Тенденции в хирургическом лечении синдрома кубитального канала: Консенсус Членов Американского Общества Хирургии Кисти// Аэша Яха, Эндрю Р. Маларкей, Райан Л. Эшбаух и Х. Брент Бамбергер // РУКА — $2017-$ С. 1-6

○ Мухина Ольга Владимировна ( personal1 @mail.ru ), Кузнецов Алексей Витальевич,

Древаль Олег Николаевич.

Журнал «Современная наука: актуальные проблемы теории и практики»

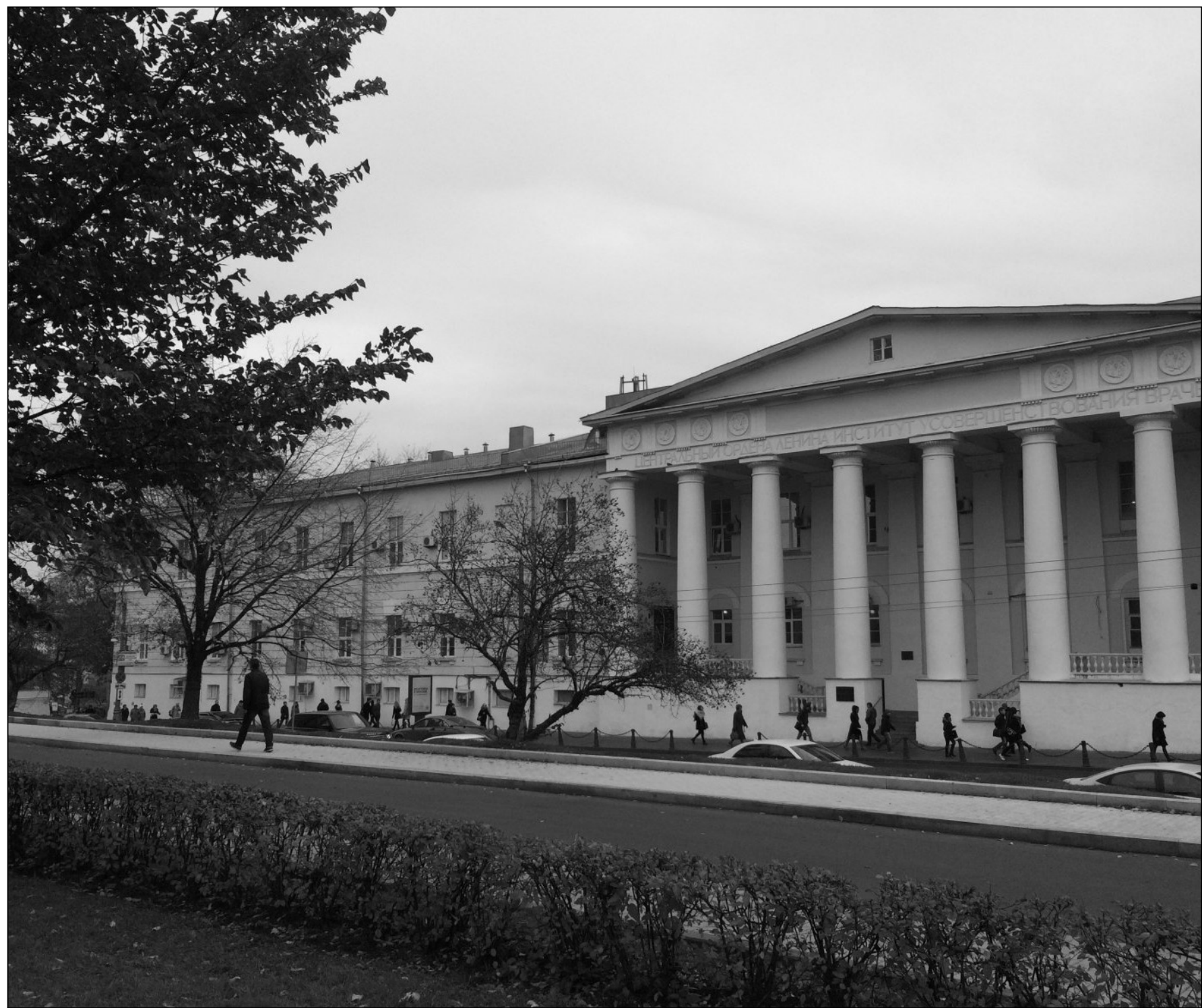

«Российская медицинская академия непрерывного профессионального образования» Министерства здравоохранения Российской Федерации 